\title{
O canteiro do poeta-arquiteto a conduta criativa de João Cabral de Melo Neto à luz de seus manuscritos
}

\author{
Francisco José Gonçalves Lima Rocha ${ }^{1}$
}

\section{Resumo}

Neste artigo repensamos a metáfora do "poeta-engenheiro", ou "poetaarquiteto", que geralmente caracteriza o processo criativo de João Cabral de Melo Neto, à luz de uma leitura genética de manuscritos de $A$ educação pela pedra. Veremos que o "arquiteto" da metáfora provém da teoria de Le Corbusier, na qual o desenho (a concepção) determina o canteiro (a execução). No entanto, a análise de transformações de estruturas por meio de reformulações textuais nos manuscritos do poeta mostra que, por vezes, o projeto, ou intenção, se transforma nos trabalhos da página-canteiro.

\section{Palavras-chave}

João Cabral de Melo Neto, arquitetura, crítica genética

Recebido em 10 de maio de 2012

Aprovado em 6 de julho de 2012

ROCHA, Francisco J. G. L., 0 canteiro do poeta-arquiteto: a conduta criativa de João Cabral de Melo Neto à luz de seus manuscritos. Revista IEB, São Paulo, n. 55, p. 127-147, 2012.

1 Doutor em Letras pela Faculdade de Filosofia, Letras e Ciências Humanas da Universidade de São Paulo e pelo Département des Études Portugaises, Brésiliennes et de l'Afrique Lusophone da Universidade Paris 8 (regime de cotutela). Atualmente, desenvolve pesquisa de pós-doutorado no Instituto de Estudos Brasileiros da Universidade de São Paulo (USP, São Paulo, SP, Brasil). Email: fjrocha@gmail.com 


\title{
The construction site of the poet-architect the creative conduct of João Cabral de Melo Neto, in the light of his manuscripts
}

\author{
Francisco José Gonçalves Lima Rocha
}

\begin{abstract}
In this article, we rethink the metaphor of the "poet-engineer" or "poet-architect", which generally characterizes the creative process of João Cabral de Melo Neto, in the light of a genetic reading of the manuscripts of "The education of the stone". We show that the "architect" of the metaphor is originated in Le Corbusier, in which the design (the conception) determines the construction site (the execution). However, the analysis, in the manuscripts, of the transformation of structures by the means of textual reformulation shows that sometimes the project, or its intention, is changed during the works on the building site, that is, while writing the page.
\end{abstract}

Keywords

João Cabral de Melo Neto, architecture, genetic criticism 


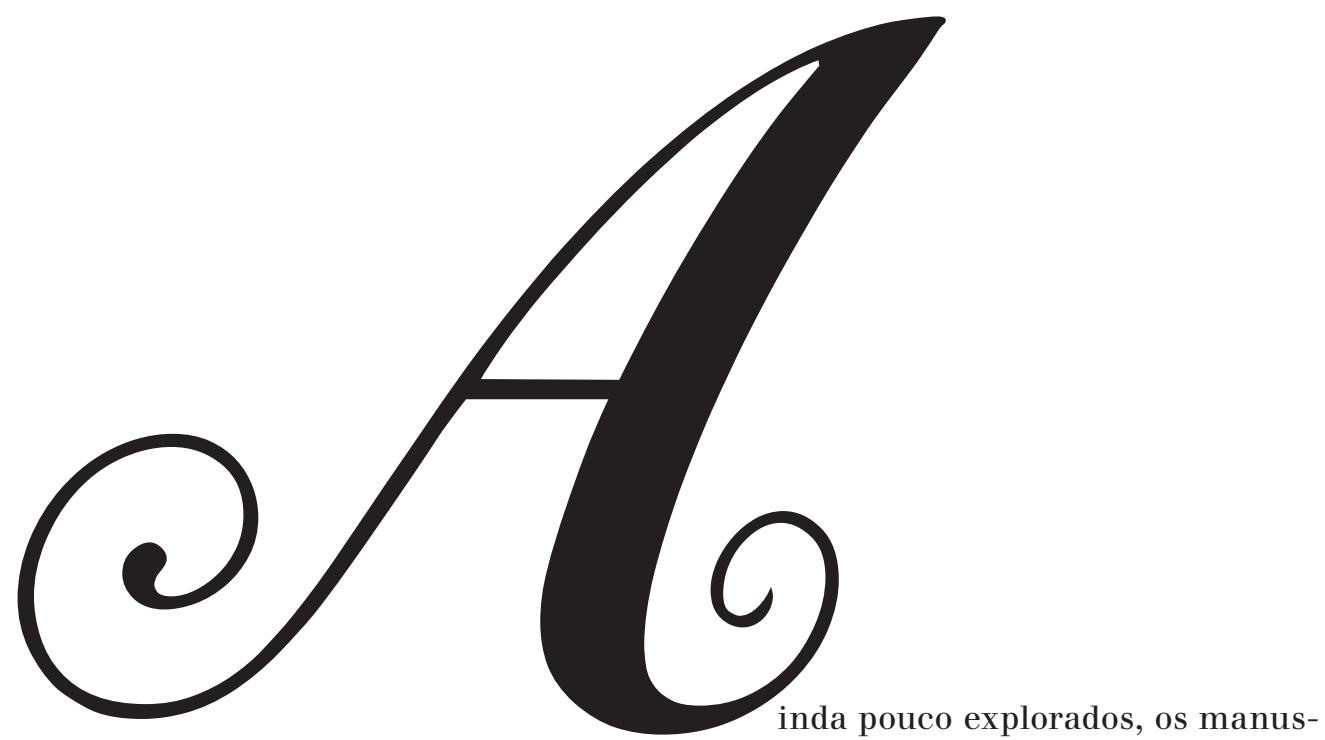

critos de João Cabral de Melo Neto, depositados na Fundação Casa de Rui Barbosa, permitem, se considerados à luz da crítica genética, aprofundar o conhecimento de um dos aspectos mais estudados da poética cabralina, relativo ao processo de criação literária. A formulação mais difundida desse processo é o epíteto "poeta-engenheiro" (ou, ainda, "poeta-arquiteto"), que quase sempre acompanha o nome João Cabral. Ela provém de uma certa interpretação das suas imagens metalinguísticas, que valoriza as metáforas técnicas, e da análise das estruturas de seus poemas, que ressalta as simetrias semânticas e formais. Neste artigo, explicitaremos os valores inerentes a essa representação arquitetural do fazer cabralino, e veremos em que medida a prática criativa legível nos documentos prototextuais do livro A educação pela pedra (1966), considerado o mais arquitetônico do autor, legitima tais valores.

\section{Desenho e canteiro}

O "construtivismo" de João Cabral, se nos fiarmos em Antonio Candido, está presente já no primeiro volume do poeta, Pedra do sono (1942). Fazendo uma leitura atenta de alguns textos do livro, o crítico afirma que neles "se nota a ordenação vigorosa que o poeta imprime ao material que lhe fornece a sensibilidade". Sendo esse material os "dados mais espontâneos da realidade", o construtivismo inicial do artista não

2 CANDIDO, Antonio. Textos de intervenção. São Paulo: Duas Cidades, 2oo2, p. 136. O texto de Antonio Candido foi publicado pela primeira vez em 1943. 
chega a ser explicado pelo crítico em termos de racionalidade arquitetônica. "Construídos com rigor", como afirma Antonio Candido, os poemas de Pedra do sono não são, porém, "um edifício racionalista"

O crítico, muito tempo depois, em um depoimento dado a Selma Vasconcelos, voltará a caracterizar o construtivismo de João Cabral de Melo Neto, contrapondo-o à "poesia derramada", à poesia que exprime emoções. Afirma Candido:

Eu acho que existe, na obra de João Cabral, muita coerência, porque, até na poesia social dele, a gente sente que sua preocupação principal é a construção. Ele é um construtor. [...] O construtor é aquele que vê o poema como um objeto a ser construído metodicamente. A emoção tem que ser transformada em palavras neutras. E, na medida em que ela é neutra, ela comove muito, enquanto a poesia derramada é indiscreta, é a poesia em que o sentimento atrapalha a forma. Parece mais expansão psicológica que construção. Isso nunca aconteceu em João Cabral, mesmo na sua poesia aplicada, na poesia para teatro. Sempre um grande construtor. Por isso, acho que o livro cujo título melhor o exprime é $O$ engenheiro. ${ }^{4}$

É justamente na recepção do terceiro livro do poeta, O engenheiro (1945), visto pelos críticos como um "edifício racionalista", que nascerá o "poeta-arquiteto". Três exemplos bastam para mostrá-lo. O primeiro é o artigo de Haroldo de Campos, "O geômetra engajado" indica o tipo de representação feita da poiética cabralina, pois o termo "geômetra" sem dúvida se refere à geometria projetiva da arquitetura. Isso se torna explícito quando o crítico lança, metaforicamente, uma hipótese sobre o processo de composição da obra:

[João Cabral de Melo Neto representa] a instauração, na poesia brasileira, de uma poesia de construção, racionalista e objetiva, contra uma poesia de expressão, subjetiva e irracionalista. Os poemas de $\mathrm{O}$ engenheiro são como que feitos a régua e a esquadro, riscados e calculados no papel. ${ }^{6}$

3 Idem, p. 137. Os grifos são nossos.

4 VASCONCELOS, Selma (org.). João Cabral de Melo Neto: retrato falado do poeta. Recife: Editora CEPE, 2009, p. 153-154.

5 CAMPOS, Haroldo de. Metalinguagem e outras metas. São Paulo: Perspectiva, 1992, p. $77^{-88 .}$

6 Idem, p. 8o-81. O grifo é nosso. 
"Riscados e calculados no papel", significa, pois, para Haroldo de Campos, a antecipação lúcida da forma e sua construção rigorosa, que estão no núcleo da metáfora arquitetônica. Os termos da citação são bem semelhantes aos de um outro crítico importante, Benedito Nunes, em uma análise através da qual tenta mostrar que, no mesmo livro, há um "ideal de lucidez poética", propriamente arquitetural, como se vê nesta passagem:

A feitura do poema, que se qualifica de máquina de comover, obedecerá analogicamente à mesma razão construtiva e geométrica que gera o projeto técnico de uma máquina e a planta de um edifício, traçados a lápis e a esquadro em uma folha de papel. ${ }^{7}$

Um último exemplo reafirma que a conduta arquitetônica por detrás da metáfora do poeta-engenheiro se descreve em termos de sobreposição da concepção ao processo realizativo. Trata-se do crítico João Alexandre Barbosa, do qual citamos o trecho seguinte, que comenta, também, o livro $O$ engenheiro:

[...] o engenheiro proposto por João Cabral tem mais de arquiteto do que de pedreiro, pois ele não é aquele que realiza por acumulação - pedra sobre pedra - mas aquele que, no branco do papel, traça a figura de um espaço que, por si mesmo, ganha faculdade de nomeação. ${ }^{8}$

Se dividirmos o processo de produção arquitetônico em dois momentos principais, o desenho e o canteiro, seguindo uma proposta de Sérgio Ferro ${ }^{9}$, vemos que, nos comentários críticos citados, há uma sobre-

7 NUNES, Benedito. João Cabral de Melo Neto. Rio de Janeiro: Vozes, 1974, p. 41.

8 BARbosa, João Alexandre. A imitação da forma. Uma leitura de João Cabral de Melo Neto. São Paulo: Duas Cidades, 1975, p. 95.

9 FERRO, Sérgio. Arquitetura e trabalho livre. São Paulo: Cosac Naif, 2006, p. 105200. Ver também, do mesmo autor, A história da arquitetura vista do canteiro. Três aulas de Sérgio Ferro. São Paulo: GFAU, 2010; e, por fim, sobre o mesmo assunto, SIMONNET, Cyrille. Dessin-chantier. Réflexions sur la genèse de l'œuvre architecturale. Genesis: Paris, n. 14, p. 111-126, 2000. Ambos os autores fazem uma crítica à sobreposição, em arquitetura, do desenho - considerado como espaço de prescrição absoluta - ao canteiro - considerado como espaço submisso de execução. A tese de Sérgio Ferro tem uma base marxista e enuncia que a progressiva transformação do desenho arquitetônico em uma pré-visão sistemática dos operações do canteiro - ideia que se desenvolve a partir da Géometrie descriptive de Gaspar Monge (1799), segundo o autor - é o efeito da violência capitalista de exploração do trabalho, que retira o savoir-faire do operário, na medida em que 
valorização do desenho ("arquiteto") com relação ao canteiro ("pedreiro"), ou, em termos gerais de poiética, da noesis (concepção) com relação à poiesis (execução), na medida em que as especificações do primeiro preveem sistematicamente as operações do segundo, o que instaura uma divisão hierárquica fortemente marcada no processo criativo.

Essa hierarquização, não por acaso, coaduna-se perfeitamente com a teoria da arquitetura de Le Corbusier, o qual dá a epígrafe de $O$ engenheiro ("machine à émouvoir"). De fato, o arquiteto suíço elevava o plano a elemento mais importante do processo de construção, propugnando uma arquitetura da prevalência do projeto sobre o canteiro: "a planta é a geradora"; "a planta está na base"; "a planta é a determinação do todo; ela é o momento decisivo", afirma ${ }^{10}$. Não somente o desenho arquitetônico se sobrepõe ao canteiro, mas a concepção em geral se sobrepõe a todo gesto executivo, dominando-o como uma ideia determinante e reguladora:

A arquitetura é uma ordenação; é no cérebro que a operação se efetua; a folha de papel não acolherá senão os sinais técnicos úteis para manifestar e transmitir esse pensamento. ${ }^{11}$

Esses princípios poiéticos de previsibilidade e controle, provenientes da arquitetura moderna, descrevem, pela voz de seus críticos, a conduta de João Cabral de Melo Neto. Nascido no terceiro livro do autor, o poeta-engenheiro teria alcançado seu ápice em A educação pela pedra, considerado o livro mais arquitetônico de Cabral. Leremos os prototextos de alguns poemas da obra a fim de determinar se o percurso genético neles recobrável necessariamente faz valer a metáfora da arquitetura tal como exposta anteriormente.

o subjuga pela simbolização arbitrária do projeto, castrando sua liberdade criativa. Essa transformação tem a seguinte cadeia de causas, conforme o autor: (1) a corrida capitalista pela mais-valia "reclama a redução da hora social média de produção"; (2) "a redução da hora social média supõe, entre outras coisas, o adensamento dos tempos operacionais mínimos"; (3) "o adensamento dos tempos precisa da transparência esmiuçada da produção dominada, do objeto a produzir e das etapas de produção"; (4) "a transparência do objeto a produzir e das etapas de produção passa pelo desenho técnico que os determina”. Ver p. 156 de Arquitetura e trabalho livre. Voltaremos às teses de Sérgio Ferro no final deste artigo.

“Trois rappels à MM. les architectes", L'esprit nouveau, n. 4, apud LUCAN, Jacques. Composition, non-composition. Architecture et théories, XIXe - XXe siècles. Lausanne: Presses polytechniques et universitaires romandes, 2o10, p. 367. Traduzimos.

11 Quand les cathédrales étaient blanches. Paris: Gonthier, s/d, apud FERRO, Sérgio. Arquitetura e trabalho livre, op. cit., p. 136. A tradução é de Sérgio Ferro. 


\section{Reformulação textual: equivalência e assimetria}

Os traços da operação parafrásica ou de reformulação textual é um dos dados mais importantes dos manuscritos de João Cabral, porque, na imensa maioria das vezes, neles já há um texto inteiramente composto (mas obviamente não acabado), que o autor modifica por meio de rasuras, configurando substituição, acréscimo, supressão e deslocamento.

Em termos gerais, a paráfrase é definida como "a reformulação, em uma situação discursiva dada, de um texto-fonte"12, ou, ainda, "a reformulação de uma sequência em termos de outra"13. No entanto, pode-se afirmar que há dois tipos de reformulação textual, conforme a relação do texto produzido com o texto de origem. Por um lado, essa relação se define em termos de equivalência. Ou seja, um texto-fonte $\mathrm{T}$ e um texto-alvo T' são equivalentes na medida em que ambos têm o mesmo conteúdo $\mathrm{C}$, ou seja, remetem ao mesmo núcleo de sentido ${ }^{14}$. Assim, pode-se dizer que a paráfrase, enquanto produção de sentido através da substituição de um enunciado por outro equivalente, não implica uma transformação do conteúdo do texto-fonte, e leva à suposição da existência de uma intenção de significação que permanece invariante e se repete em toda a cadeia parafrásica. Essa concepção está presente na teoria do linguista Bernard Pottier:

No plano intencional (nível conceitual ou mental), o autor quer dizer um evento (tomado em sua acepção mais larga), e seu procedimento se dá através de uma confrontação com seu saber (linguístico e enciclopédico) a fim de escolher os componentes que lhe parecem mais adequados. Entrando assim na língua natural, ele vai continuar a elaboração de uma mensagem que será enunciada. Não sendo esta satisfatória com relação à intenção de partida, o autor pode repetir a operação um número indeterminado de vezes. Chega-se assim a um texto composto de vários reditos [redites], todos diferentes entre si, mas ligados a um mesmo ponto de partida. ${ }^{15}$

12 FUCHS, Catherine. Paraphrase et énonciation. Paris: Ophrys, 1994, p. 3. Traduzimos.

13 Idem. Élements pour une approche énonciative de la paraphrase dans les brouillons de manuscrits. In: HAY, Louis (org.). La genèse du texte: les modèles linguistiques. Paris: Éditions du CNRS, 1987, p. 86. Traduzimos.

14. Ver FUCHS, Catherine. Paraphrase et énonciation. op. cit., p. 26.

15 POTTIER, Bernard. La paraphrase textuelle dans ses fondements théoriques. Cahiers de linguistique hispanique médiévale, n. 14-15, 1990, p. 37. Traduzimos. 
Esse procedimento parafrásico assemelha-se perfeitamente à conduta arquitetônica, já que o resultado final deve corresponder à forma-projeto concebida (a "intenção inicial"), sendo todo o percurso reformulativo determinado pela exigência de uma realização equivalente de tal forma.

Por outro lado, a paráfrase pode ser definida a partir da noção de assimetria. O texto-fonte T e texto-alvo T' são assimétricos na medida em que a passagem para T' implica a alteração do sentido de T, podendo resultar em um texto completamente diferente. A reformulação como produção de uma cadeia textual assimétrica exclui a existência de uma intenção de significação invariante, pois a intenção devém outra, ou somente se estabelece, durante o processo reformulativo. Essa concepção de paráfrase é amplamente teorizada pela linguista Catherine Fuchs, que não deixa de pensá-la no âmbito da análise dos manuscritos, nos quais, segundo a autora, ocorre o fenômeno de "auto-reformulação". Citemos:

Consideremos um outro caso de reformulação [...]: trata-se da sequência mais ou menos longa de auto-reformulações, através da qual um scriptor constrói progressivamente seu texto. A especificidade desse tipo de reformulação reside no fato de que não existe um texto-fonte completamente constituído desde o início. [...] De forma evidente, o sujeito dispõe raramente de um conteúdo pronto para ser revestido com tal ou tal forma de expressão; sob modalidades diversas, que variam de um sujeito a outro, é a um incessante ir-e-vir entre forma e fundo que se entrega o scriptor, sendo o conteúdo elaborado e estabilizado progressivamente através de diversas tentativas de formulação. ${ }^{16}$

Assim, na reformulação assimétrica, o caráter intrinsecamente variante do conteúdo a ser expresso, ou mesmo a inexistência de toda intenção de significação, já que esta se elaboraria somente no percurso reformulativo, leva-nos a considerar aqui um processo de escritura que destoa do procedimento da arquitetura projetiva.

\section{Um exemplo de equivalência}

Encontram-se nos manuscritos de João Cabral de Melo Neto reformulações textuais que produzem tanto enunciados equivalentes quanto

16 FUCHS, Catherine. op. cit., p. 17. Traduzimos. 
assimétricos. Das primeiras, reproduziremos aqui apenas um exemplo. Referimo-nos ao prototexto do poema "Para a feira do livro", cuja primeira parte da primeira unidade transcrevemos diplomaticamente a seguir.

Est. cl.

\author{
PARA A FEIRA DO LIVRO \\ GARTAZES PARA O LIVRO
}

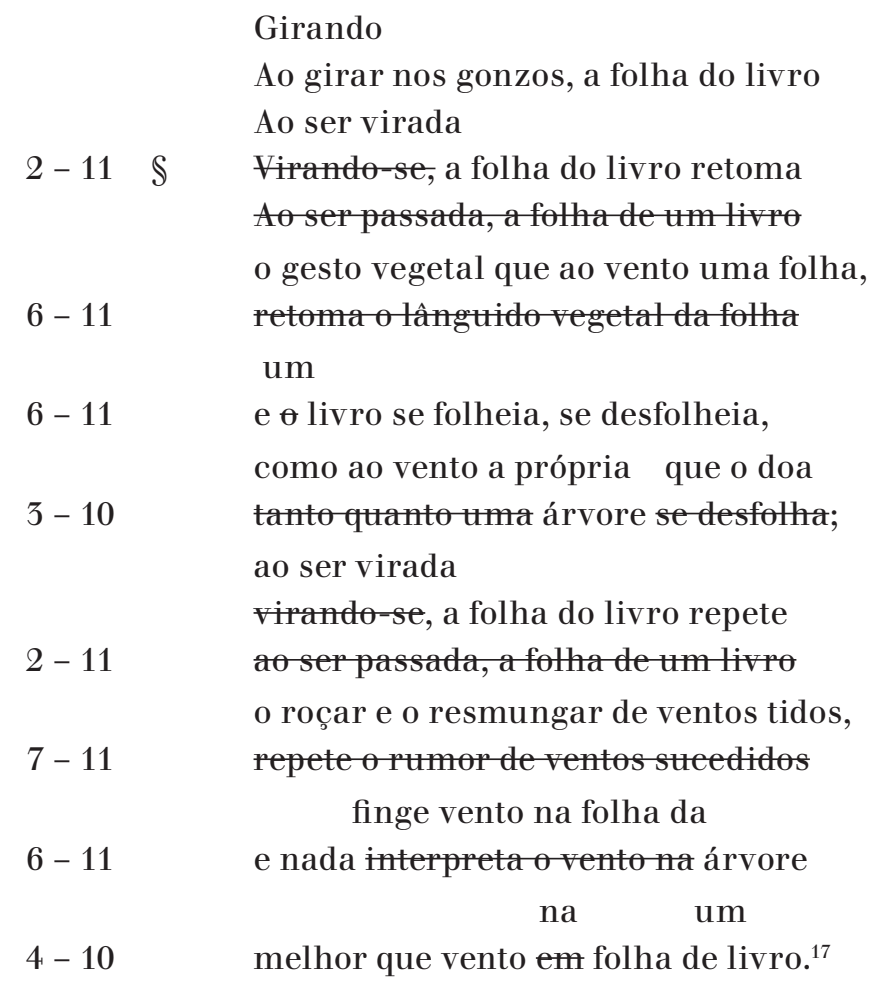

Um breve esclarecimento quanto à numeração feita à esquerda do documento, presente nos manuscritos de quase todos os textos que compõem A educação pela pedra. Trata-se da contagem efetuada por Cabral do número de sílabas dos versos, cuja métrica ele decompõe irregularmente em dois "hemistíquios". O primeiro algarismo corresponde

17 Fundação Casa de Rui Barbosa, fundo João Cabral de Melo Neto, pasta Pi. A educação pela pedra, fólio 3 . 
ao número de sílabas até a primeira pausa e o segundo, ao número de sílabas do verso inteiro. Os números sempre dizem respeito ao verso reformulado, muito embora não corresponda, por vezes, à métrica da versão final publicada. Por exemplo, no sexto verso, o primeiro "hemistíquio" tem sete sílabas e o verso total, onze ("o roçar e o resmungar/ de ventos tidos"). Mas na versão publicada, a primeira parte tem oito sílabas, o verso total, treze ("fricativas e labiais/de ventos antigos").

Agora, com respeito às reformulações semânticas, sempre considerando o manuscrito e a última versão do poema, temos três versões diferentes da unidade inicial. Primeira:

Ao ser passada, a folha de um livro retoma o lânguido vegetal da folha, e o livro se folheia, se desfolheia, tanto quanto uma árvore se desfolha; ao ser passada, a folha de um livro repete o rumor de ventos sucedidos e nada interpreta o vento na árvore melhor que vento em folha de livro.

A segunda, considerando as últimas reformulações:

Girando nos gonzos, a folha do livro retoma

o gesto vegetal que ao vento uma folha, e um livro se folheia, se desfolheia, como ao vento a própria árvore que o doa; ao ser virada, a folha do livro repete o roçar e o resmungar de ventos tidos, e nada finge vento na folha da árvore melhor que vento na folha de um livro.

Finalmente, a terceira, a versão publicada:

Folheada, a folha de um livro retoma o lânguido e vegetal da folha folha, e um livro se folheia ou se desfolha como sob o vento a árvore que o doa; folheada, a folha de um livro repete fricativas e labiais de ventos antigos, e nada finge vento em folha de árvore 
melhor do que vento em folha de livro. ${ }^{18}$

A comparação entre as três versões mostra que uma mesma intenção permanece, a de mostrar a similitude que há entre o movimento e a sonoridade das folhas de um livro ao ser folheado, e o movimento e a sonoridade das folhas de uma árvore balançadas pelo vento. Isso se verifica pela permanência, nas três versões, dos sintagmas "a folha de um (do) livro retoma", "a folha de um livro repete", e o que ela retoma e repete é movimento e o som do vento na árvore. A representação do som eólico sofre algumas reformulações, da seguinte maneira:

rumor de ventos sucedidos

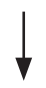

roçar e resmungar de ventos tidos

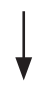

fricativas e labiais de ventos antigos

Essas paráfrases ocorrem por meio de relações parassinonímicas com valor metafórico. Na versão datilografada, a representação é ortonímica, expressa pela palavra "rumor". A primeira reformulação mantém, por um lado, a ortonímia, por meio do verbo "roçar" (o som produzido pelo contato do vento com as coisas), e, por outro lado, opera uma personificação ao associar o som do vento ao "resmungar", ao falar por entre os dentes. A segunda reformulação, por sua vez, abandona completamente a representação ortonímica, mantendo a metáfora personificante, mas agora por meio de conceitos fonemáticos ("fricativas e labiais"). Essa representação do som do vento nas folhas por meio desses conceitos vai de par com uma maior disseminação do fonema /f/, também fricativo e labial, no trecho citado. De fato, na primeira versão temos sete palavras com o fonema: quatro vezes a palavra "folha", a palavra "folheia", a palavra "desfolheia" e a palavra "desfolha". Na segunda versão, temos oito, quais sejam, cinco vezes a palavra "folha", a palavra "folheia", a palavra "desfolheia" e a palavra "finge". Na terceira versão, onde o poeta lança mão da expressão "fricativas e labiais", o fonema /f/ se repete dez vezes, nas cinco aparições da palavra "folha", nas duas da palavra "folheada", na palavra "folheia", na palavra "desfolha" e na palavra

18 MELO NETO, João Cabral de. A educação pela pedra e depois. Rio de Janeiro: Nova Fronteira, 1997, p. 39 . 
"finge". Isso mostra que a finalidade das reformulações é um progressivo reforço da correspondência entre a representação semântica e a textura sonora do poema, estando tal isomorfismo presente desde a primeira formulação. $\mathrm{O}$ autor, portanto, produz textos equivalentes que realizam uma intenção inicial.

\section{Exemplos de assimetrias}

Os exemplos de reformulações assimétricas têm um interesse especial, pois dão a ver um percurso mais trajetual que projetual da escritura cabralina, problematizando, assim, o procedimento arquitetônico. Damos aqui um exemplo que mostra como a estrutura de um poema, concebida e realizada de uma certa maneira, é transformada posteriormente através de reformulações. Referimo-nos a "Catar feijão", de cujo manuscrito integral damos, a seguir, uma transcrição diplomática: 
Gatando

SOBRE CATAR FEIJÃO

$$
\begin{aligned}
& \text { 1. Catar feijão/confina com escrever } \\
& 4-9 \quad \begin{array}{l}
\text { joga-se o grão/na água do alguidar } \\
\text { 3-11 } a<s>\text { palavra }<\text { s }>\text {, na da folha de papel, }
\end{array} \\
& \begin{array}{l}
\text { então } \\
\text { e depois, joga-se fora o que boiar. }
\end{array}
\end{aligned}
$$$$
\begin{aligned}
& \text { 7-12 J.R } \\
& \text { 4-10 -10 }
\end{aligned}
$$

Este de certo não é concessivo! Onde

fui buscar a ideia? Ele me

parece um: é certo que!!..

- não sou obrigado $\mathrm{a}^{19}$

19 Fundação Casa de Rui Barbosa, fundo João Cabral de Melo Neto, pasta Pi. A educação pela pedra, fólio 59 . 
C. (conj. ilativa)

Ora, nesse catar feijão há um risco,

8-11 2. Gerto, nessa forma de eatar feijão

o de que nos grãos entre

$6-9$

resta tm riseo: de neles, por entre,

um qualquer ou

4 - 9 meter-se um grão, indigesto de pedra

grão)

4 - 10 ou inquebrável, Cde quebrar um dente.

quando se cata palavras:

$3-10 \quad$ Certo não, eatando palarra: a pedra

uma pedra dá à

7 - 12 mete entre a frase/um grão efetivo:

7 - $11 \quad$ brida a leitura fluviante, flutual,

5 - 10 açula a atenção, isca-a com o risco. ${ }^{20}$

20 Fundação Casa de Rui Barbosa, fundo João Cabral de Melo Neto, pasta Pi. A educação pela pedra, fólio 6o. Damos aqui a versão publicada:

Catar feijão se limita com escrever:

jogam-se os grãos na água do alguidar

e as palavras na da folha de papel;

e depois, joga-se fora o que boiar.

Certo, toda palavra boiará no papel,

água congelada, por chumbo seu verbo:

pois para catar esse feijão, soprar nele,

e jogar fora o leve e oco, palha e eco.

2

Ora, nesse catar feijão entra um risco:

o de que entre os grãos pesados entre

um grão qualquer, pedra ou indigesto,

um grão imastigável, de quebrar dente.

Certo não, quando ao catar palavras:

a pedra dá à frase seu grão mais vivo:

obstrui a leitura fluviante, flutual,

açula a atenção, isca-a com o risco.

In: MELO NETO, João Cabral de. A educação pela pedra e depois. Rio de Janeiro:

Nova Fronteira, 1997, p. 16-17. 
Como bem observou Benedito Nunes, a estrutura do poema "Catar feijão" é determinada pelos nexos lógicos estabelecidos por meio de conjunções e advérbios:

Podemos constatar aí a função estruturante dos nexos lógicos, tanto conjunções como advérbios (certo, pois, ora, certo não) numa forma mista, proso-poética. Valorizando-se as conexões lógicas da linguagem, os moldes que ficam à mostra, na construção do poema, são mais expositivos do que descritivos. ${ }^{21}$

Considerando a modalidade das formas lógicas - valor declarativo (certo, certo não) e ilativo (pois, ora) - que ligam as proposições do poema, pode-se dizer que aí há um continuum argumentativo que estabelece a similaridade e a dessemelhança entre o ato de catar feijão e o de escrever. O poema é, pois, assertivo e hipotático.

Ora, vemos pela leitura do manuscrito que tal estrutura não é concebida a priori e lucidamente. O valores das formas que conectam as semipartes na primeira versão (certo, aí/então, certo, certo não) constituíam todo um outro nexo entre essas semipartes, um nexo concessivo-paratático. O interessante é a motivação dessa mudança. Ela ocorre devido a um erro de... cálculo. Esse erro está expresso explicitamente na nota metalinguística escrita pelo próprio autor, na parte de baixo do fólio, e que comenta a segunda semiparte:

Esse de certo não é concessivo. Onde fui buscar a ideia? Ele me parece um: é certo que!!..

- não sou obrigado a

A percepção desse “engano” será responsável por toda a série de reformulações dos nexos lógicos. De fato, percebendo que "certo" não tinha o valor semântico que intencionara, o autor abandona a construção concessivo-paratática projetada e a refaz a partir de um "certo" com valor assertivo, substituindo "então" por "pois", e "certo" (concessivo) por "ora”. Diversa da primeira, a nova estrutura lógica é expositiva e hipotática. Essa nova estrutura decorre de um erro e surge como que por acaso, à revelia do projeto original do autor. A predeterminação formal não é, portanto, tão rígida assim em Cabral, como seria desejável numa arquitetura projetual. Os acidentes do percurso fazem o autor lançar mão de seu livre-arbítrio. Lembremos a nota metalinguística: "não estou

21 NUNES, Benedito. op. cit., p. 135. 
obrigado a". Quer dizer: o poeta não se vê obrigado a insistir na estrutura que intencionara. Aqui, a necessidade do desenho se submete às imprevisibilidades do canteiro, que engendra estruturas diferentes durante o processo de composição.

Poderíamos dar outros exemplos que mostram como, nos manuscritos de Cabral, as estruturas se transformam mesmo depois do poema inteiramente escrito. Mas devido aos limites do presente artigo, preferimos indicar rapidamente que essas mudanças interferem na concepção global do livro A educação pela pedra. Basta comparar o documento publicado por Antonio Carlos Secchin na revista COLÓQUIO/Letras ${ }^{22}$, e que o crítico chama de "planta baixa" da obra, com os manuscritos dos poemas. Constatar-se-á que, na verdade, a "planta" é posterior à composição dos textos, o que inverte a lógica arquitetônica. Mais: dezessete poemas têm, em sua primeira versão, uma estrutura diferente da que é indicada na "planta": doze no nível das relações entre as metades ou unidades e cinco no nível das relações entre as semipartes ${ }^{23}$. Além disso, diversos manuscritos de poemas do livro Serial (1961) e, sobretudo, de poemas de A escola das facas (1980), também problematizam a estrutura projetual da conduta do poeta-engenheiro ${ }^{24}$.

\section{De novo, desenho e canteiro}

Voltemos a esse tipo de estrutura em João Cabral. Vimos que a fonte para sua formulação é o sistema arquitetural de Le Corbusier, que concebe uma arquitetura fortemente planificada. Mas essa extrema planificação, como mostra Sérgio Ferro, pode ser considerada apenas "retórica". Seria o caso, por exemplo, do convento de La Tourette, cujo dossiê arquitetônico é estudado pelo arquiteto brasileiro. Na concepção dessa obra, Le Corbusier teria proposto uma estrutura aérea, como se pode ler nesta sua passagem:

22 SECCHIN, Antonio Carlos. Um original de João Cabral de Melo Neto. COLÓQUIO/ Letras. Paisagem tipográfica. Homenagem a João Cabral de Melo Neto (1920-199o), 2000, n. 157/158, p. 159 .

23 Para uma comparação detalhada da "planta" com os prototextos ver ROCHA, Francisco José Gonçalves Lima. Representação e prática da criação literária na obra de João Cabral de Melo Neto. Análise textual e prototextual. Tese de Doutorado em Letras, Faculdade de Filosofia, Letras e Ciências Humanas, Universidade de São Paulo, Brasil e Département des Études Portugaises, Brésiliennes et de l'Afrique Lusophone, Universidade Paris 8, França.

24 Esses manuscritos também são analisados na tese citada na nota anterior. 
Aqui, nesse terreno, que era tão móvel, tão fugidio, descendo, escorregando, eu disse: não vou tomar por base a terra porque ela escapa. Tomemos por base, no alto, a horizontal do prédio no topo, mediremos todas as coisas a partir daí e atingiremos o chão no momento em que o tocarmos. ${ }^{25}$

O comentário que Sérgio Ferro faz desse trecho é extremamente crítico:

Curiosa posição para um “construtor": partir do teto. A edificação real, coitada, tem sempre que sair do chão. O oxímoro, o teto é a base, anuncia o quiasmo das relações entre o desenho e o canteiro: lá, o andamento vai da ficção à construção, aqui, da construção à ficção. Quase todos os comentaristas do convento o olham assim, de cima para baixo, pondo de cara a construção real de lado. ${ }^{26}$

Assim, há um desequilíbrio entre a estrutura fictícia, desenhada, e a estrutura real, realizada: concebe-se o convento a partir do teto, mas toda edificação é plantada na terra. Há mais: segundo Ferro, o convento de La Tourette dá a impressão de “corresponder a uma lógica forte, bem pensada e segura de si” ${ }^{27}$, isto é, dá a impressão de que foi realizado conforme as prescrições precisas da concepção. Nada disso. O projeto de Le Corbusier era irrealizável e teve que se render às evidências do canteiro. É Sérgio Ferro quem o afirma:

O que parece bem pensado frequentemente é obra do acaso. Algumas vigas e as lajes do "piano" e da sacristia, perfuradas por "canhões de luz" (no "piano") e por "metralhadoras de luz" (na sacristia) [...] eram irrealizáveis. O que é surpreendente da parte de um "construtor". Às pressas foi convocada uma empresa de construção de pontes, que resolveu o impasse recorrendo ao concreto pretendido - numa de suas primeiras aplicações em edifício na França, solução cara e então insegura. E o fruto do acaso [...] foi apresentado pelo mestre como contribuição ao avanço tecnológico. ${ }^{28}$

25 apud Ferro, Sérgio. op. cit., p. 220. A tradução é de Sérgio Ferro.

26 Idem, ibidem.

27 Idem, p. 215.

28 Idem, p. 216. 
Podemos retomar diferentemente, agora, a metáfora do poetaarquiteto consagrada pela crítica literária. Como vimos, ela representa um fazer controlado que realiza rigorosamente um projeto preconcebido. Porém, na medida em que, como vimos, o processo reformulativo em Cabral integra mudanças de sentido e estruturas, inclusive casualmente originadas, talvez seja necessário representar o fazer cabralino não somente por meio de uma po(i)ética do projeto, mas também por meio de uma po(i)ética do canteiro. Isso significa dizer que o desenho deixa de prescrever a obra completa e autoritariamente, e se rende ao fato de que é no canteiro que ela se resolve (ou não). No nível prototextual da obra de João Cabral de Melo Neto haveria, também, uma arquitetura próxima daquela que Sérgio Ferro expõe nos seguintes termos:

[...] na arte, a concepção é pouca se isolada - como dizia Mallarmé a Degas que, apesar de ter muitas ideias, não conseguia escrever um soneto. O desenho só conta quando se perde na matéria e volta outro, transformado pelo trabalho que o redescobre transubstanciado. ${ }^{29}$

É esse movimento de ir e vir entre desenho (intenção) e matéria (linguagem), com retificações e desvios, que gostaríamos de reter para caracterizar o processo criativo de João Cabral, o que se coaduna com o que o próprio poeta escreveu sobre o escrever:

Escrever jamais é sabido;

o que se escreve tem caminhos. ${ }^{30}$

29 Idem, ibidem.

30 Versos do poema "O postigo". In: MELO NETO, João Cabral de.A educação pela pedra e depois. op. cit., p. 276. 


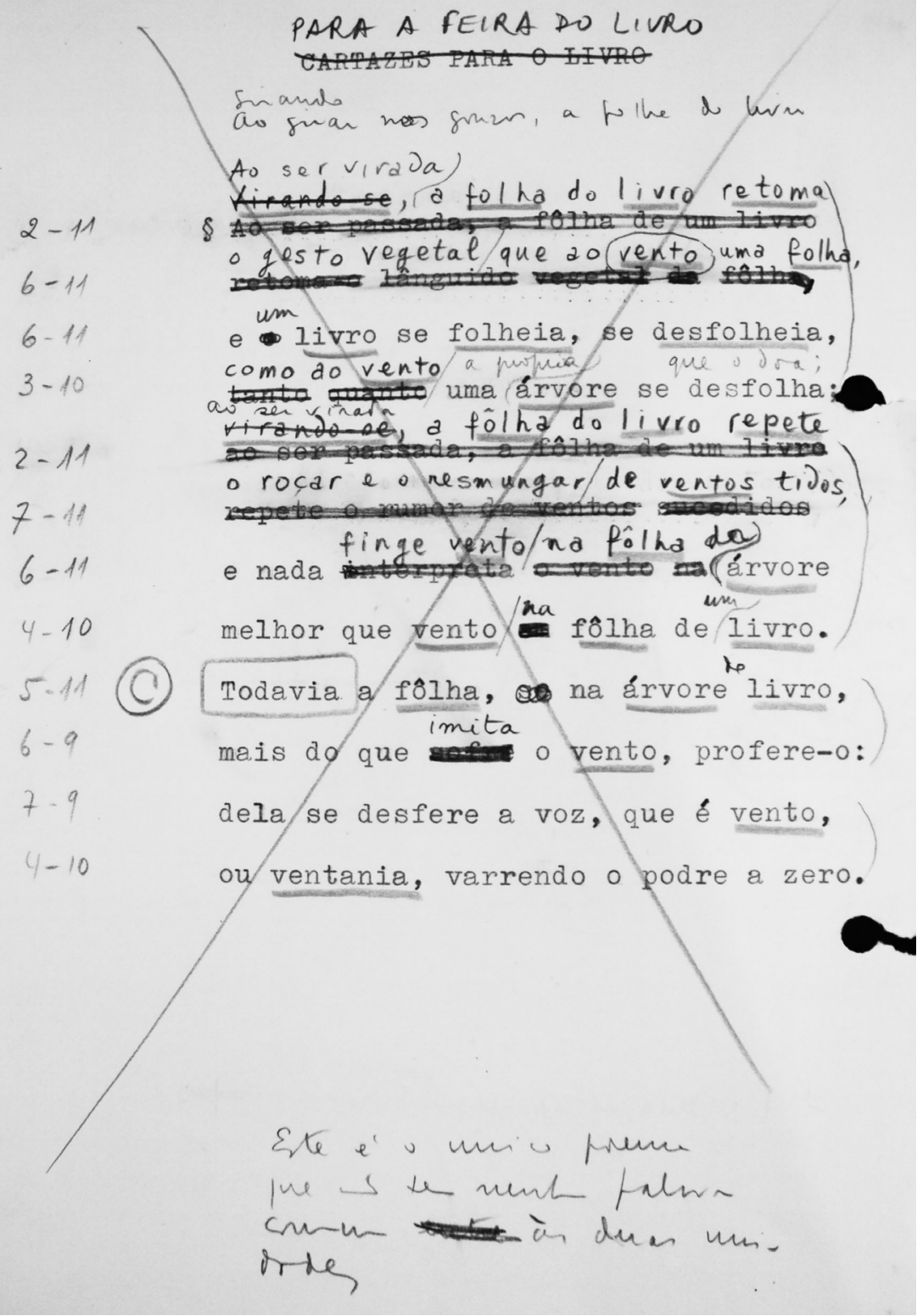

Datiloscrito reformulado do poema "Para a feira do livro". Fundo João Cabral de Melo Neto, Fundação Casa de Rui Barbosa, pasta Pi. A educação pela pedra I, fólio 3 frente. 


\section{Est.due}

\section{Ext+ \\ SUEE CATAR FEIJAO}

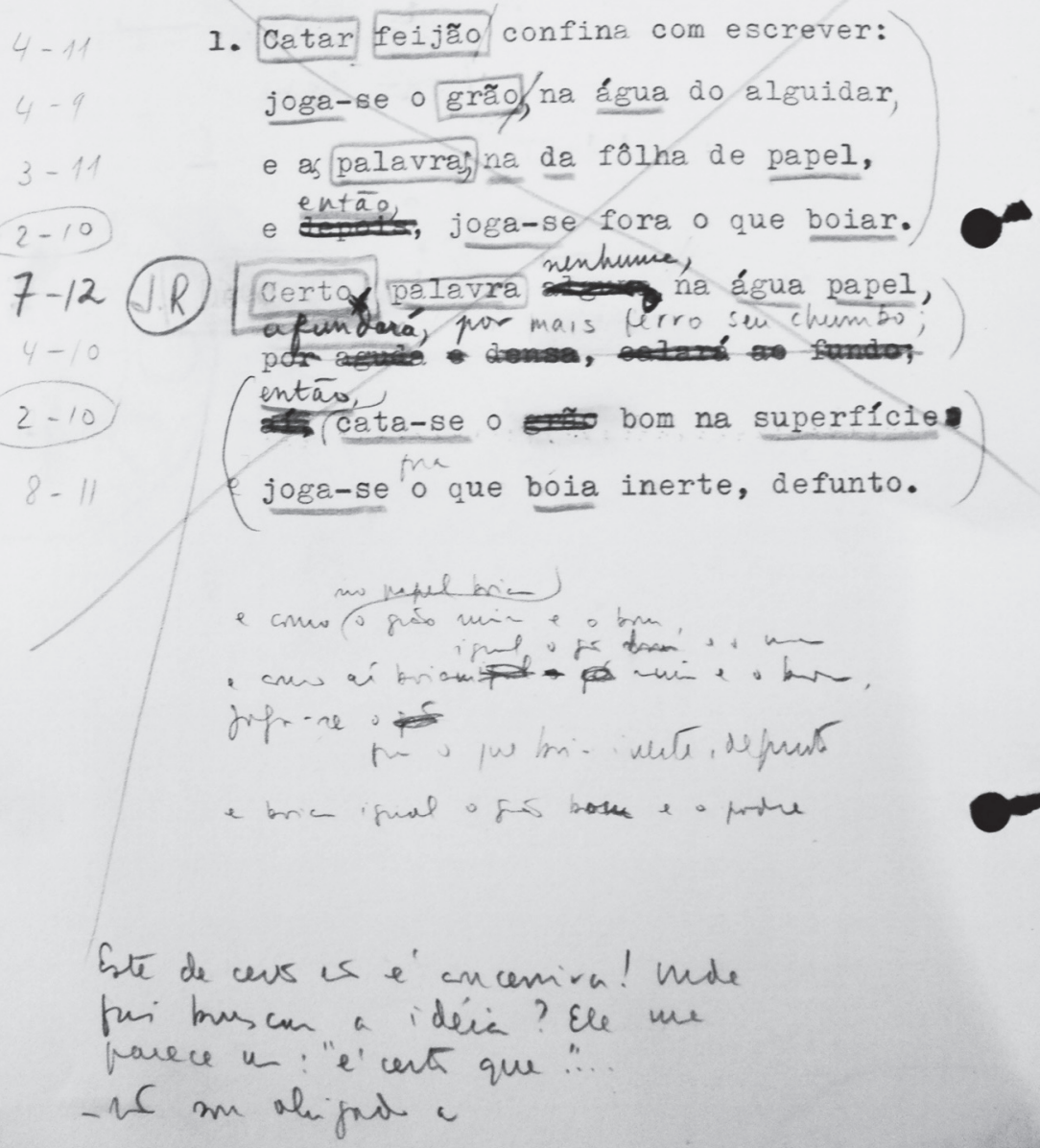

Datiloscrito reformulado do poema "Catar feijão". Fundo João Cabral de Melo Neto, Fundação Casa de Rui Barbosa, pasta Pi. A educação pela pedra I, fólio 59 frente. 


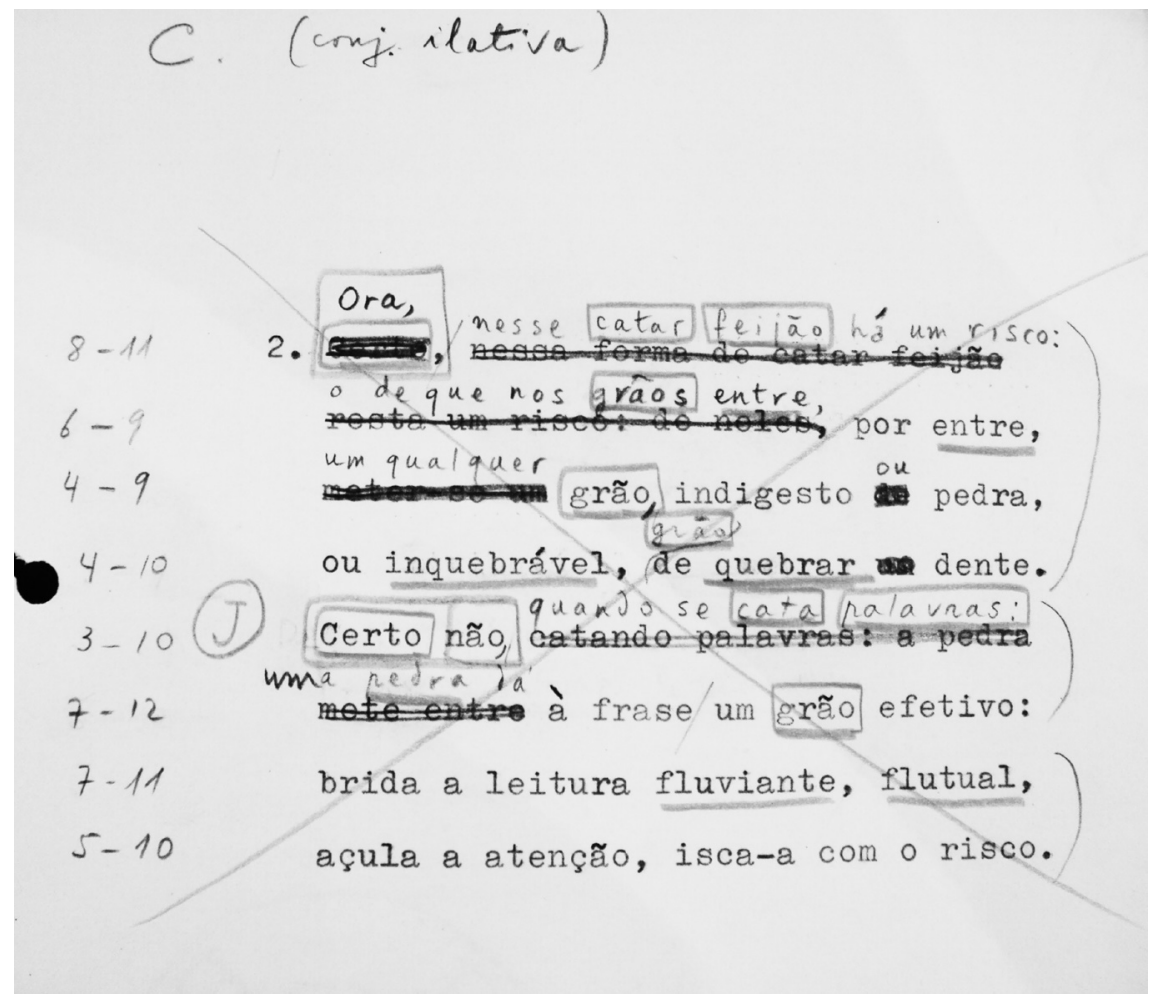

Datiloscrito reformulado do poema “Catar feijão”. Fundo João Cabral de Melo Neto, Fundação Casa de Rui Barbosa, pasta Pi. A educação pela pedra I, fólio 60 frente. 
